\title{
Tele-Monitoring of Cancer Patients' Rhythms during Daily Life Identifies Actionable Determinants of Circadian and Sleep Disruption
}

\author{
Francis Lévi ${ }^{1,2,3, *}$, Sandra Komarzynski ${ }^{1,2}{ }^{-}$, Qi Huang ${ }^{1,4}\left(\mathbb{D}\right.$, Teresa Young ${ }^{5}$, Yeng Ang ${ }^{6,7}$, \\ Claire Fuller ${ }^{8}$, Matei Bolborea ${ }^{1} \oplus$, Julia Brettschneider ${ }^{4}$, Joanna Fursse ${ }^{1}$, Bärbel Finkenstädt ${ }^{2,4}$, \\ David Pollard White ${ }^{9,10}$ and Pasquale Innominato ${ }^{1,2,8}$ \\ 1 Cancer Chronotherapy Team, Warwick Medical School, Coventry CV4 7AL, UK; \\ S.Komarzynski@warwick.ac.uk (S.K.); Q.Huang.6@warwick.ac.uk (Q.H.); M.Bolborea@warwick.ac.uk (M.B.); \\ Joanna.fursse@nhs.net (J.F.); Pasquale.Innominato@wales.nhs.uk (P.I.) \\ 2 European Laboratory U935, Institut National de la Santé et de la Recherche Médicale (INSERM), \\ Paris-Saclay University, 94801 Villejuif, France; B.F.Finkenstadt@warwick.ac.uk \\ 3 Hepato-Biliary Centre, Paul Brousse Hospital, Assistance Publique Hôpitaux de Paris (AP-HP), \\ 94800 Villejuif, France \\ 4 Department of Statistics, University of Warwick, Coventry CV4 7AL, UK; Julia.Brettschneider@warwick.ac.uk \\ 5 Mount Vernon Cancer Centre, East and North Hertfordshire NHS Trust, Northwood, Middlesex HA6 2RN, \\ UK; Teresa.young2@nhs.net \\ 6 Salford Royal NHS Foundation Trust, Salford M6 8HD, UK; Yeng.Ang@srft.nhs.uk \\ 7 Gastrointestinal Sciences, Division of Diabetes, Endocrinology and Gastroenterology, Faculty of Biology, \\ Medicine and Health, University of Manchester, Manchester M13 9PL, UK \\ 8 North Wales Cancer Treatment Centre, Ysbyty Gwynedd, Betsi Cadwaladr University Health Board, \\ Bangor LL57 2PW, UK; Claire.Fuller2@wales.nhs.uk \\ 9 Division of Sleep and Circadian Disorders, Brigham and Women's Hospital, Harvard Medical School, \\ Boston, MA 02130, USA; dpwhite@partners.org \\ 10 Philips Respironics, Murrysville, PA 15668, USA \\ * Correspondence: F.Levi@warwick.ac.uk; Tel.: +44-2476-575-132
}

Received: 30 June 2020; Accepted: 14 July 2020; Published: 17 July 2020

\begin{abstract}
The dichotomy index $(\mathrm{I}<\mathrm{O})$, a quantitative estimate of the circadian regulation of daytime activity and sleep, predicted overall cancer survival and emergency hospitalization, supporting its integration in a mHealth platform. Modifiable causes of $\mathrm{I}<\mathrm{O}$ deterioration below $97.5 \%-(\mathrm{I}<\mathrm{O})_{\text {low }}$-were sought in 25 gastrointestinal cancer patients and 33 age- and sex-stratified controls. Rest-activity and temperature were tele-monitored with a wireless chest sensor, while daily activities, meals, and sleep were self-reported for one week. Salivary cortisol rhythm and dim light melatonin onset (DLMO) were determined. Circadian parameters were estimated using Hidden Markov modelling, and spectral analysis. Actionable predictors of $(\mathrm{I}<\mathrm{O})_{\text {low }}$ were identified through correlation and regression analyses. Median compliance with protocol exceeded 95\%. Circadian disruption- $(\mathrm{I}<\mathrm{O})_{\text {low }}$-was identified in $13(52 \%)$ patients and four $(12 \%)$ controls $(p=0.002)$. Cancer patients with $(\mathrm{I}<\mathrm{O})_{\text {low }}$ had lower median activity counts, worse fragmented sleep, and an abnormal or no circadian temperature rhythm compared to patients with I $<\mathrm{O}$ exceeding $97.5 \%-(\mathrm{I}<\mathrm{O})_{\text {high }}-(p<0.012)$. Six $(\mathrm{I}<\mathrm{O})_{\text {low }}$ patients had newly-diagnosed sleep conditions. Altered circadian coordination of rest-activity and chest surface temperature, physical inactivity, and irregular sleep were identified as modifiable determinants of $(\mathrm{I}<\mathrm{O})_{\text {low }}$. Circadian rhythm and sleep tele-monitoring results support the design of specific interventions to improve outcomes within a patient-centered systems approach to health care.
\end{abstract}

Keywords: gastro-intestinal cancer; circadian rhythms; sleep; circadian regulation; biomarkers; patient-reported outcome measures; cortisol; melatonin; age; sex 


\section{Introduction}

Chronic disease patients represent the largest burden for our health care system, and are at highest risk of acute complications, as currently seen in the COVID-19 pandemic [1,2]. There is a need for a comprehensive patient-centered health care system, which gathers and analyzes patients' data during daily life, and provides them and their families and hospital physicians with information enabling shared decision-making procedures [3,4]. Such a "domomedicine" system will anticipate and prevent emergency hospitalizations through proactive interventions, based on early warning signals extracted from critical health functions dynamics tele-monitoring. This presents an immense opportunity for progress through circadian medicine to integrate our rapidly increased understanding of how molecular circadian clocks work and control cellular and organismic physiologies over the course of $24 \mathrm{~h}$ [5]. Dedicated and non-invasive biomarkers, such as rest-activity, body temperature, sleep, cortisol, and melatonin, can help to diagnose circadian alterations, and monitor disease or treatment effects on the circadian timing system (CTS), especially for cancer patients [6]. The CTS links a central circadian pacemaker, the hypothalamic suprachiasmatic nuclei, to the widespread cellular genetic clocks through the generation of an array of physiological and hormonal rhythms [7]. Circadian oscillations are generated in each mammalian cell by a molecular oscillator involving some 15 specific genes regulating each other through transcriptional and post transcriptional feedback loops [8,9]. The alternation of days and nights, social interactions, and meal timing, i.e., the daily routines, help to calibrate the period of the CTS, to enhance its coordination and robustness, and to reset its timing [6].

In cancer patients, strong links have been shown between overall survival and rest-activity, salivary cortisol, and temperature circadian biomarkers [10-14]. The disruption of the circadian rest-activity rhythm was shown to be a significant predictor for emergency hospitalization three days later in cancer patients on chemotherapy $[15,16]$. Overall survival, as well as global and specific domains of health-related quality-of-life in large cohorts of cancer patients were predicted by the dichotomy index $(\mathrm{I}<\mathrm{O})$, defined as the relative amount of activity In-bed that is below the median activity out-of-bed [11-13]. Previous research had further shown that $\mathrm{I}<\mathrm{O}$ ranged from 50 to $100 \%$ in over 500 patients with advanced or metastatic cancer. The median $\mathrm{I}<\mathrm{O}$ value has consistently been close to $97.5 \%$ in cancer patients, compared to $99.5 \%$ in healthy subjects $(p<0.0001)$, thus highlighting the clinical relevance of this parameter [17]. Thus, I < O values below $97.5 \%$, have been associated with more prevalent and severe systemic symptoms [18], poorer global and specific domain measured health-related quality of life, and shorter progression-free and overall survival [10,12,13,19-22] For instance, in 436 patients with metastatic colorectal cancer, the median overall survival rate was 21.6 months (range: 17.8-25.5) for those with $\mathrm{I}<\mathrm{O}$ above the median value of $97.5 \%$, compared to 11.9 months (range: 10.4-13.3) for those with a lower $\mathrm{I}<\mathrm{O}$ (Log-rank $p<0.001)$. Multivariate analyses retained continuous $\mathrm{I}<\mathrm{O}$ as a joint predictor of both overall survival and progression-free survival $(p<0.001)$ [12]. The integration of such information on circadian rhythms into daily oncologic practice could indeed advance personalized and precision cancer medicine.

This can now be done, since the monitoring of multiple physiological rhythms, jointly with symptoms and other data, has become possible through mobile e-Health platforms linking Bluetooth Low Energy (BLE) connected sensors and other devices to a central server via a General Packet Radio Service (GPRS) gateway. Such a domomedicine platform proved to be acceptable and technically reliable in field studies involving 223 people, including shift workers and cancer patients [23]. Appropriate statistical methods were developed for estimating CTS function in an individual subject during their daily life [24,25]. Here, we identify the main actionable determinants of circadian and sleep disruption through tracking two circadian biomarkers in real time in two clinical studies involving a pooled sample of size 58 comprising both cancerous and non-cancerous individuals. Our findings support the crucial potential of a comprehensive patient-centered digital therapeutics system for boosting medical progress. 


\section{Results}

\subsection{Study Flow, Participants' Characteristics, Compliance, and Data Quality}

\subsubsection{Cancer Patients}

Similar numbers of cancer patients were classified as either $(\mathrm{I}<\mathrm{O})_{\text {low }}$ (13 patients) or $(\mathrm{I}<\mathrm{O})_{\text {high }}$ (12 patients) based on the initial $72 \mathrm{~h}$ of accelerometry recording at chest level (Figure 1a). There were 21 males $(84 \%)$ and four females (16\%) with an overall median age of 66 years (range 40 to 82 ) and a good WHO performance status (Table 1). Most patients had primary colorectal cancer, metastatic disease, and prior chemotherapy. Seventeen of the 25 cancer patients (65\%) had at least one additional comorbidity, including $58 \%$ in the $(\mathrm{I}<\mathrm{O})_{\text {high }}$ group and $77 \%$ of the patients in the $(\mathrm{I}<\mathrm{O})_{\text {low }}$ group. Twenty-two cancer patients $(88 \%)$ were taking at least one concurrent medication, which were mostly related to the treatment of associated cardiovascular $(N=11,44 \%)$, endocrine/metabolic $(N=10,40 \%)$, and/or respiratory $(N=6,24 \%)$ pathologies. The distribution of performance status, comorbidities and associated medications intakes did not differ significantly between both $\mathrm{I}<\mathrm{O}$ groups. Three patients (12\%) were suffering from anxiety and/or depression according to results from the hospital anxiety and depression scale (HADS) questionnaire. Overall subjective sleep quality, reported with the Pittsburgh sleep quality index (PSQI), was good or fairly good (with a global score $\leq 10$ ) for 18 patients. No significant differences were found for patient characteristics as well as for PSQI and HADS scores according to $\mathrm{I}<\mathrm{O}$ category.

\subsubsection{Controls}

Of the 33 evaluated participants (89\% of those included), there were 15 males and 18 females, including 15 participants aged 40 to 78 years of age (Figure 1b, Table 1). Three control subjects (33\%) had past medical conditions and eight (24\%) reported a mild and medically controlled pathologic condition (24.3\%). Eight control subjects took one or more daily medications. No control subject took any medication known to influence circadian rhythms, such as beta-blockers, melatonin or agonists, or glucocorticoids. A single participant was taking low dose aspirin for thrombosis prevention.

The cancerous participants tended to have a larger BMI, as compared to the controls. On the other hand, the distribution of chronotypes assessed with the Morningness-Eveningness Questionnaire (MEQ) was strikingly similar for patients in both $\mathrm{I}<\mathrm{O}$ categories as well as the control group, with morning types being predominant. On average, the control participants were younger than the cancer patients with $(\mathrm{I}<\mathrm{O})_{\text {high }}(p<0.0001)$. The majority of the controls were employed or students while the patients in the $(\mathrm{I}<\mathrm{O})_{\text {high }}$ group were mostly retired or not working $(p=0.002)$. No ongoing medical condition was documented in $76 \%$ of the controls, while $58 \%$ of the patients in the $(\mathrm{I}<\mathrm{O})_{\text {high }}$ group had one or more medical conditions in addition to their cancer $(p=0.003)$.

\subsubsection{Compliance}

The median overall compliance with the study protocol was $98 \%$ in cancer patients and $96 \%$ in controls. It exceeded $96 \%$ for $75 \%$ of the cancer patients irrespective of $\mathrm{I}<\mathrm{O}$ category, and $93 \%$ for $75 \%$ of the controls irrespective of sex or age. These results highlighted the exceptional quality of the tele-transmitted and other datasets observed during daily life, for both advanced cancer patients outside the hospital setting and controls. 


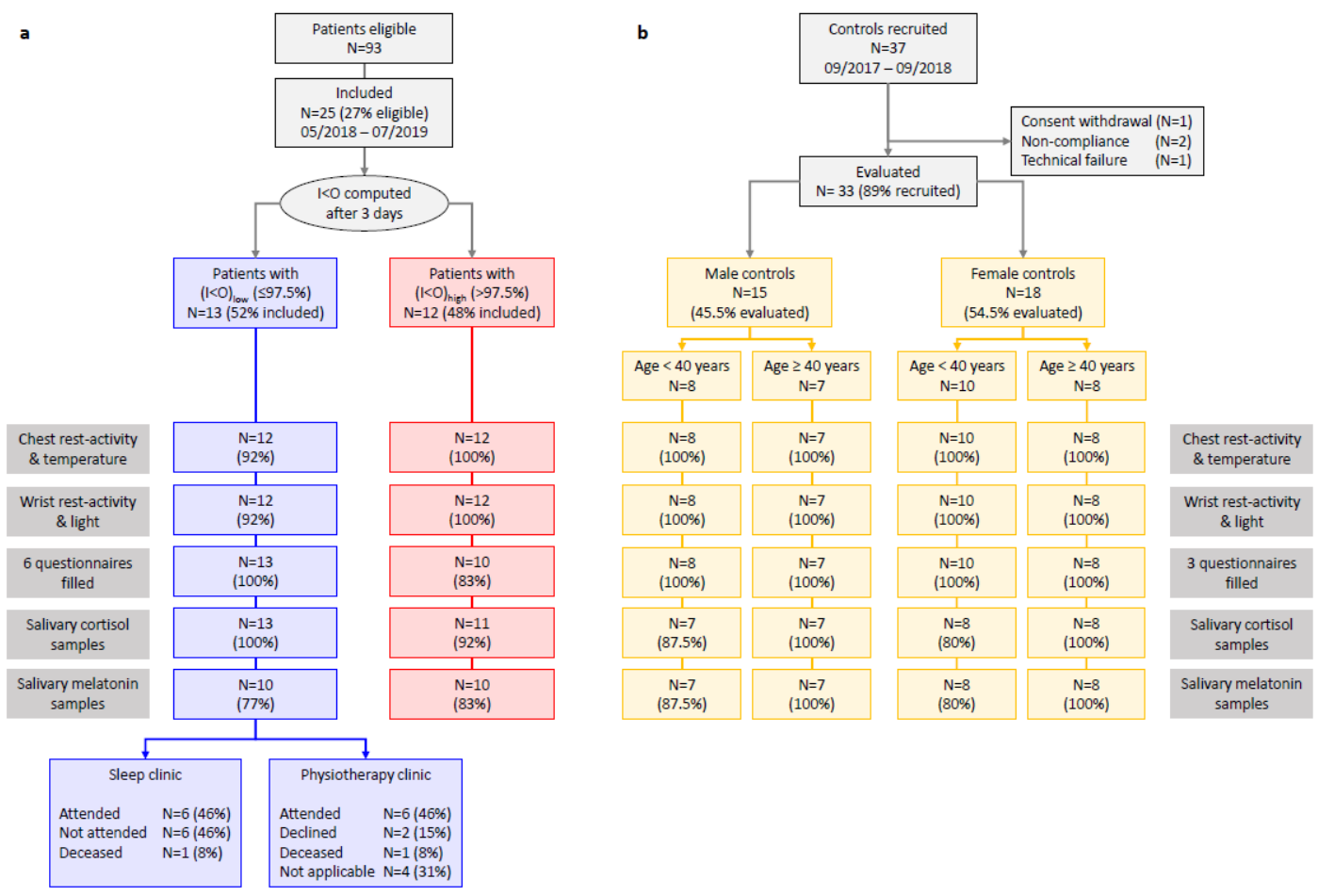

Figure 1. Consort diagram. Flow diagrams of both studies showing the enrollment of subjects and the variables that were measured. (a) Cancer patients, as categorized according to the a priori defined threshold of the dichotomy index $\mathrm{I}<\mathrm{O}$. Chest rest-activity and temperature not available for one patient due to logistics issues. Wrist rest-activity and light exposure pattern not available for one patient due to patient non-compliance. Chronotype not available for one patient. Cortisol, melatonin, diary and the M.D. Anderson Symptom Inventory (MDASI) questionnaires not provided by one patient. No or insufficient melatonin or cortisol samples for two patients. (b) Controls, stratified according to age and sex (parameters reported here are the ones which are common to both studies). Three controls did not provide any salivary samples as they were recruited before inclusion of salivary samples collection to the protocol.

\subsection{Tele-Transmitted Rest-Activity Patterns}

The circadian pattern in rest-activity was characterized by large inter-subject differences for both cancer patients and controls. For cancer patients, the $(\mathrm{I}<\mathrm{O})_{\text {low }}$ group clearly had worse chest rest-activity rhythm parameters than the $(\mathrm{I}<\mathrm{O})_{\text {high }}$ group (Figure 2$)$. As could be expected, the median $\mathrm{I}<\mathrm{O}$ values, computed over the full 7-day study span differed significantly between both groups $\left(p<0.0001\right.$, Figure 3a). In the $(\mathrm{I}<\mathrm{O})_{\text {low }}$ group, compared to the $(\mathrm{I}<\mathrm{O})_{\text {high }}$ group, there was a nearly $40 \%$ reduction in activity in moderately (MA) or highly active (HA) states $(p=0.0014)$, and circadian amplitude in activity $(p<0.0001)$, a significant $4 \%$ decrease in the estimated probability of staying in the rest state (P1-1) $(p=0.01)$, a circa $40 \%$ reduction in the estimated autocorrelation coefficient (r24) $(p=0.0012)$, and a circa 30\% decrease in the rhythm index (RI) $(p<0.0001)$ (Figure 3b-d). On the other hand, rest durations (Figure 3e), center-of-rest times, and circadian acrophase of rest-activity were similar between both groups (Figure 4). 
Table 1. Participants' main characteristics. When not specified the data are presented as Number of subjects (\%).

\begin{tabular}{|c|c|c|c|c|c|c|}
\hline \multirow[b]{2}{*}{ Number of Participants } & \multirow[b]{2}{*}{ Cancer Patients 25} & \multirow[b]{2}{*}{$\begin{array}{l}\quad(\mathrm{I}<\mathrm{O})_{\text {low }} \\
\text { Cancer Group } 13\end{array}$} & \multirow[b]{2}{*}{$\begin{array}{l}\quad(\mathrm{I}<\mathrm{O})_{\text {high }} \\
\text { Cancer Group } 12\end{array}$} & \multirow[b]{2}{*}{ Controls 33} & \multicolumn{2}{|c|}{$p$-Values ${ }^{1}$} \\
\hline & & & & & $\begin{array}{c}(\mathrm{I}<\mathrm{O})_{\text {low }} \text { vs. } \\
(\mathrm{I}<\mathrm{O})_{\text {high }} \text { (Cancer) }\end{array}$ & $\begin{array}{c}(\mathrm{I}<\mathrm{O})_{\text {high }} \text { (Cancer) } \\
\text { vs. Controls }\end{array}$ \\
\hline \multicolumn{7}{|l|}{ Sex } \\
\hline $\mathrm{M}$ & $21(84.0)$ & $11(84.6)$ & $10(83.3)$ & $15(45.5)$ & \multirow{2}{*}{1} & \multirow{2}{*}{$0.04 *$} \\
\hline $\mathrm{F}$ & $4(16.0)$ & $2(15.4)$ & $2(16.7)$ & $18(54.5)$ & & \\
\hline \multicolumn{7}{|l|}{ Age (years) } \\
\hline Median & 66 & 66 & 70 & 35 & \multirow{3}{*}{0.568} & \multirow{2}{*}{$<0.0001^{* * * *}$} \\
\hline Range & $40-82$ & $40-80$ & $42-82$ & $21-78$ & & \\
\hline \multicolumn{6}{|l|}{ BMI } & \\
\hline Median & 27.5 & 27.5 & 26.9 & 24.4 & \multirow{3}{*}{0.511} & \multirow[b]{2}{*}{0.216} \\
\hline Range & $19.8-38.8$ & $22.4-38.8$ & $19.8-33.7$ & $18.9-42.0$ & & \\
\hline \multicolumn{6}{|l|}{$(\mathrm{I}<\mathrm{O})_{72 \mathrm{~h}}(\%)$} & \\
\hline Median & 97.4 & 90.4 & 98.7 & NA & \multirow{2}{*}{$0.0017^{* *}$} & \multirow[b]{2}{*}{ NA } \\
\hline Range & $67.6-100$ & $67.6-97.4$ & $97.7-100$ & NA & & \\
\hline \multicolumn{7}{|l|}{ Work status } \\
\hline Employed or self-employed & $8(32.0)$ & $5(38.5)$ & $3(25.0)$ & $15(45.5)$ & \multirow{4}{*}{0.673} & \multirow{3}{*}{$0.002^{* *}$} \\
\hline Student & $0(0)$ & $0(0)$ & $0(0)$ & $11(33.3)$ & & \\
\hline Retired or not working & $17(68.0)$ & $8(61.5)$ & $9(75.0)$ & $7(21.2)$ & & \\
\hline \multicolumn{6}{|l|}{ Chronotype } & \\
\hline Definite morning & $3(12)$ & $1(8)$ & $2(17)$ & $5(15.2)$ & \multirow{5}{*}{0.408} & \multirow{5}{*}{0.594} \\
\hline Moderate morning & $12(48)$ & $8(62)$ & $4(33)$ & $10(30.3)$ & & \\
\hline Intermediate & $9(36)$ & $4(31)$ & $5(42)$ & 15 (45.5) & & \\
\hline Moderate evening & $0(0)$ & $0(0)$ & $0(0)$ & $3(9.1)$ & & \\
\hline Not available & $1(4)$ & $0(0)$ & $1(8)$ & $0(0)$ & & \\
\hline \multicolumn{7}{|c|}{ Ongoing medical condition (other than cancer) } \\
\hline None & $8(32.0)$ & $3(23.1)$ & $5(41.7)$ & $25(75.8)$ & \multirow{3}{*}{0.362} & \multirow{3}{*}{$0.003 * *$} \\
\hline $1-2$ & $8(32.0)$ & $6(46.2)$ & $2(16.7)$ & $7(21.2)$ & & \\
\hline$\geq 3$ & $9(36.0)$ & $4(30.8)$ & $5(41.7)$ & $1(3.0)$ & & \\
\hline \multicolumn{7}{|c|}{$\begin{array}{l}\text { Concurrent medications (apart from } \\
\text { cancer treatments) }\end{array}$} \\
\hline 0 & $3(12.0)$ & $1(7.7)$ & $2(16.7)$ & $25(75.8)$ & \multirow{3}{*}{0.866} & \multirow{3}{*}{$<0.0001 * * *$} \\
\hline $1-2$ & $12(48.0)$ & $7(53.8)$ & $5(41.7)$ & $8(24.2)$ & & \\
\hline$\geq 3$ & $10(40.0)$ & $5(38.5)$ & $5(41.7)$ & $0(0)$ & & \\
\hline
\end{tabular}


Table 1. Cont

\begin{tabular}{|c|c|c|c|c|c|c|}
\hline \multirow[b]{2}{*}{ Number of Participants } & \multirow[b]{2}{*}{ Cancer Patients 25} & \multirow[b]{2}{*}{$\begin{array}{c}(\mathrm{I}<\mathrm{O})_{\text {low }} \\
\text { Cancer Group } 13\end{array}$} & \multirow[b]{2}{*}{$\begin{array}{c}(\mathrm{I}<\mathrm{O})_{\text {high }} \\
\text { Cancer Group } 12\end{array}$} & \multirow[b]{2}{*}{ Controls 33} & \multicolumn{2}{|c|}{$p$-Values ${ }^{1}$} \\
\hline & & & & & $\begin{array}{c}(\mathrm{I}<\mathrm{O})_{\text {low }} \text { vs. } \\
(\mathrm{I}<\mathrm{O})_{\text {high }} \text { (Cancer) }\end{array}$ & $\begin{array}{c}(\mathrm{I}<\mathrm{O})_{\text {high }}(\text { Cancer }) \\
\text { vs. Controls }\end{array}$ \\
\hline \multicolumn{7}{|l|}{ Site of primary tumor } \\
\hline Colorectal & $14(56.0)$ & $5(38.5)$ & $9(75.0)$ & NA & \multirow{2}{*}{0.111} & \multirow[b]{2}{*}{ NA } \\
\hline Other & $11(44.0)$ & $8(61.5)$ & $3(25.0)$ & NA & & \\
\hline \multicolumn{7}{|l|}{ Cancer status } \\
\hline No residual tumor & $2(8.0)$ & $2(15.4)$ & $0(0)$ & NA & \multirow{3}{*}{0.561} & \multirow{3}{*}{ NA } \\
\hline Locally advanced cancer & $6(24.0)$ & $3(23.1)$ & $3(25.0)$ & NA & & \\
\hline Metastatic disease & $17(68.0)$ & $8(61.5)$ & $9(75.0)$ & NA & & \\
\hline \multicolumn{7}{|l|}{ Number of metastatic sites } \\
\hline 0 & $8(32.0)$ & 5 & 3 & NA & \multirow{3}{*}{0.861} & \multirow{3}{*}{ NA } \\
\hline $1-2$ & $13(52.0)$ & 6 & 7 & NA & & \\
\hline$\geq 3$ & $4(16.0)$ & 2 & 2 & NA & & \\
\hline \multicolumn{7}{|l|}{ Main metastatic sites } \\
\hline Liver & $9(36.0)$ & $3(23.1)$ & $6(50.0)$ & NA & \multirow{4}{*}{0.721} & \multirow{4}{*}{ NA } \\
\hline Lymph nodes & $9(36.0)$ & $5(38.5)$ & $4(33.3)$ & NA & & \\
\hline Lungs & $8(32.0)$ & $5(38.5)$ & $3(25.0)$ & NA & & \\
\hline Other & $5(20.0)$ & $2(15.4)$ & $3(25.0)$ & NA & & \\
\hline \multicolumn{7}{|l|}{ Prior cancer treatments } \\
\hline Surgery & $13(52.0)$ & $6(46.1)$ & $7(58.3)$ & NA & \multirow{3}{*}{0.508} & \multirow{3}{*}{ NA } \\
\hline Radiotherapy & $8(32.0)$ & $2(15.4)$ & $6(50.0)$ & NA & & \\
\hline Chemotherapy & $20(80.0)$ & $10(76.9)$ & $10(83.3)$ & NA & & \\
\hline
\end{tabular}

Abbreviation: NA: not applicable, ${ }^{1}$ Differences between the $(\mathrm{I}<\mathrm{O})_{\text {high }}$ and the $(\mathrm{I}<\mathrm{O})_{\text {low }}$ cancer patients and between the cancer patients and controls were tested with two-tailed Welch's $t$-tests for continuous variables or Fisher's exact test for categorical variables. The corresponding $p$-values are shown as follows: ${ }^{* * * *} p<0.0001 ;{ }^{* *} 0.001<p \leq 0.01 ;{ }^{*} 0.01<p \leq 0.05$. 



Figure 2. Rest-activity states estimation. (a) Rest-activity plots of one patient in the $(\mathrm{I}<\mathrm{O})_{\text {high }}$ group, with an $\mathrm{I}<\mathrm{O}$ value of $99.1 \%$. Top row: time series of rest-activity with yellow line indicating the most likely state using hidden Markov modelling (HMM) decoding. Bottom row: state probability plot showing the cumulative probabilities of low (blue), intermediate (pink) and high (red) active states. The color bars represent the patient's self-reported sleeping and physical exercise spans. (b) Rest-activity plots of an example patient in the $(\mathrm{I}<\mathrm{O})_{\text {low }}$ group, with an $\mathrm{I}<\mathrm{O}$ value of $86.5 \%$. (c) Circadian state probability plot from harmonic HMM of the rest-activity pattern of the patient shown in (a). The panel shows the periodic time profile of the three state probabilities plotted as a cumulative manner analogous to the state probability plot with same color coding as in the bottom row of (a). (d) Circadian state probability plot from harmonic HMM of the rest-activity pattern of the patient shown in (b).

The $\mathrm{I}<$ Os of the cancer patients, including those in the $(\mathrm{I}<\mathrm{O})_{\text {high }}$ group, were significantly worse than those of the controls (median values, 99.2 vs. 97.3\%, $p=0.008$ ) (Figure 3a). This was also the case for the levels of the activity (177.3 vs. $106.1 \mathrm{acc} / \mathrm{min}$ in HA states, $p<0.0001$ ), the rest probability P1-1 (0.97 vs. 0.94, $p=0.005$ ), but not for circadian amplitude of activity, r24, RI, center-of-rest and the rest duration (Figure 3b-f). The four parameters (I < O, P1-1, RI, r24) were strongly correlated with each other in pairwise comparisons, except for r24 and P1-1 (Figure 3g). The latter is not surprising, as P1-1 has a focus on rest periods only, while r24 is also influenced by regular recurrence during the active periods.

\subsection{Tele-Transmitted Chest Surface Temperature Patterns}

The $(\mathrm{I}<\mathrm{O})_{\text {low }}$ cancer patients had markedly deteriorated temperature rhythm parameters compared to the $(\mathrm{I}<\mathrm{O})_{\text {high }}$ ones (Figure $\left.5 \mathrm{a}, \mathrm{b}\right)$. A dominant circadian rhythm in chest surface temperature was found for $92 \%$ of the patients in the $(\mathrm{I}<\mathrm{O})_{\text {high }}$ group, but only for $58 \%$ in the $(\mathrm{I}<\mathrm{O})_{\text {low }}$ group $(p=0.15)$, who also displayed an approximately $40 \%$ reduction in temperature circadian amplitude $(p=0.021)$ (Figure $5 \mathrm{c})$. Furthermore, nine out of 12 patients in the $(\mathrm{I}<\mathrm{O})_{\text {high }}$ group (75\%) had a physiologic circadian rhythm in temperature, with an acrophase at night between 22:01 and 07:00. This was the case only for two out of 12 patients who provided recordings in the 
$(\mathrm{I}<\mathrm{O})_{\text {low }}$ group $(16.6 \%)(p=0.0123)$ (Figure $\left.5 \mathrm{~d}\right)$, while the other ten patients $(83.5 \%)$ had either an abnormal temperature rhythm $(n=5)$ or no detectable rhythmic pattern at all $(n=5)$.
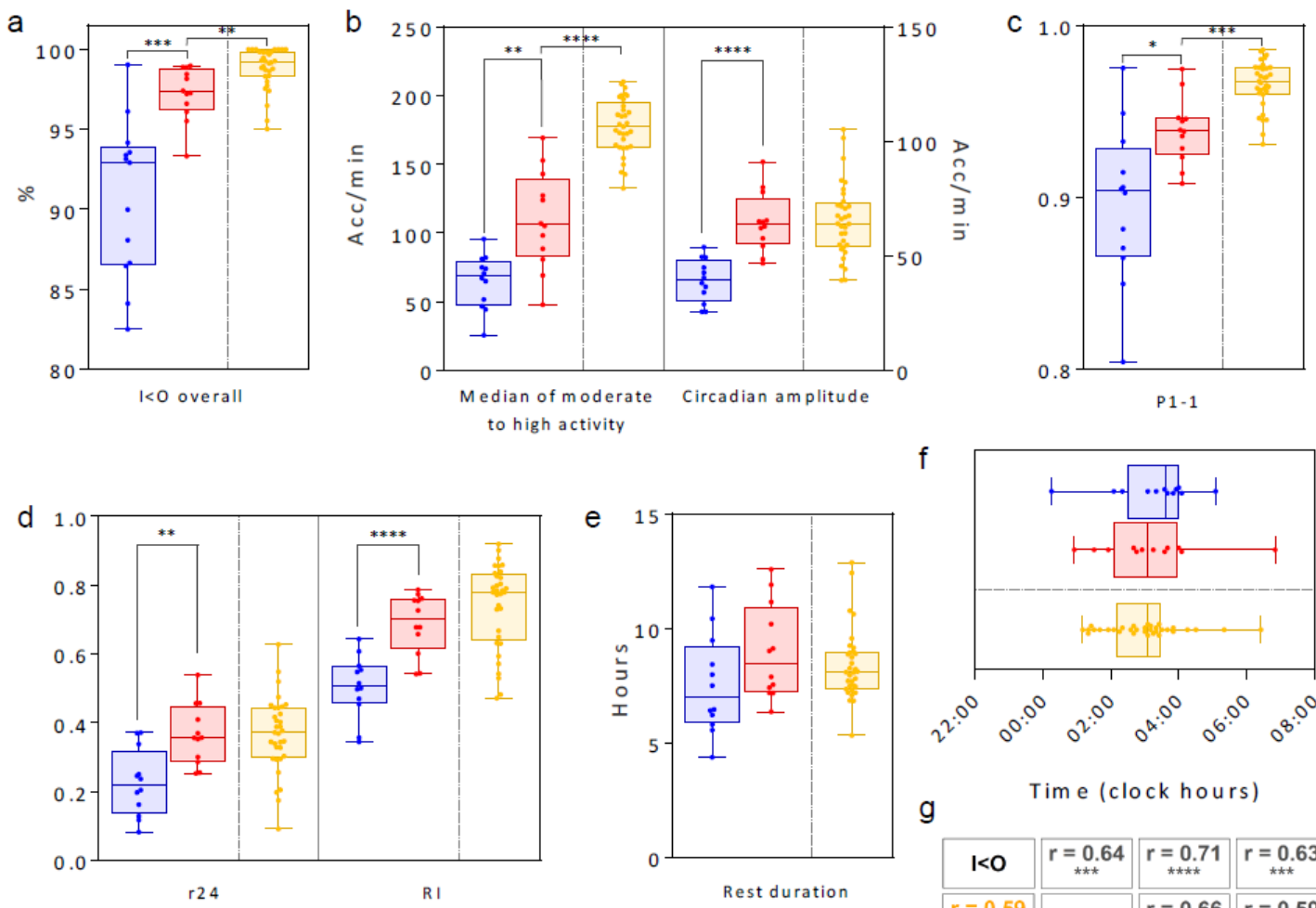

$(1<0)_{\text {low }}$ cancer group

$(1<0)_{\text {high }}$ cancer group

Controls $f$

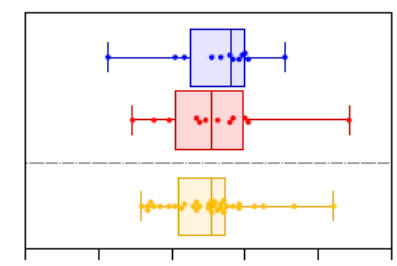

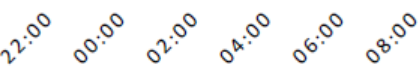

g Time (clock hours)

\begin{tabular}{|c|c|c|c|}
\hline $1<0$ & $r=\underset{\star \star \star}{0.64}$ & $r=\underset{\star \star \star \star \star \star}{0.71}$ & $r=0.63$ \\
\hline $\mathrm{r}=\underset{* * * \pi}{0.59}$ & RI & $r=0.66$ & $\mathrm{r}=\underset{* \star}{0.59}$ \\
\hline $\mathrm{r}=0.7$ & $r=0.57$ & P1-1 & $r=\underset{\Lambda}{0.39}$ \\
\hline$r=0.38$ & $r=\underset{*}{0.42}$ & $r=0.08$ & r24 \\
\hline
\end{tabular}

Figure 3. Box plots comparing the main parameters of the tele-transmitted rest-activity patterns in $(\mathrm{I}<\mathrm{O})_{\text {low }}$ and $(\mathrm{I}<\mathrm{O})_{\text {high }}$ cancer groups, and in the controls. (a) Box plots of $\mathrm{I}<\mathrm{O}$ values computed over 7 days for each $\mathrm{I}<\mathrm{O}$ patient group and controls. (b) Median of MA and HA activity states and circadian amplitude (spectral analysis). (c) P1-1 (HMM). (d) R24 and Rhythm Index. (e) Estimated rest duration. (f) Center-of-rest time. (g) Correlation matrices of the rest-activity rhythms parameters for cancer patients (black) and controls (yellow). In (a-e), the bars represent the extremes and bold lines inside the box plots plot median levels. Values for each individual are plotted as jittered dots to better show the distribution. Levels of significance: ${ }^{* * *} p \leq 0.0001 ;{ }^{* * *} 0.0001<p \leq 0.001 ;{ }^{* *} 0.001<p \leq 0.01$; ${ }^{*} 0.01<p \leq 0.05 ;^{\wedge} 0.05<p \leq 0.1$ (two-tailed Welch's modified $t$-test (a-e); Pearson's correlation (f)).

We therefore concluded that the disruption of the circadian rhythm in chest surface temperature was strongly associated with that of the rest-activity circadian rhythm, thus, supporting a major and selective alteration of the central circadian coordination in cancer patients with a low $\mathrm{I}<\mathrm{O}$. In contrast, temperature circadian acrophase (Figure 4) and amplitude, as well as the relative rate of subjects with a physiologic circadian temperature rhythm, were similar between the $(\mathrm{I}<\mathrm{O})_{\text {high }}$ cancer patients and controls ( $p=0.23, p=0.49$, and $p=0.49$, respectively) (Figure $5 c, d$ ).

\subsection{Lifestyle, Cortisol and Dim Light Melatonin Patterns}

No significant or relevant differences were found for the external time cues that synchronize circadian rhythms both between the two $\mathrm{I}<\mathrm{O}$ cancer groups, and between cancer patients and controls (Appendix A, Figure S1). 
Salivary cortisol time series exhibited consistent diurnal changes from early morning "highs" to evening "lows" over two consecutive days in most individual controls and cancer patients, irrespective of their I $<$ O category (Figure $6 \mathrm{a}$ ).

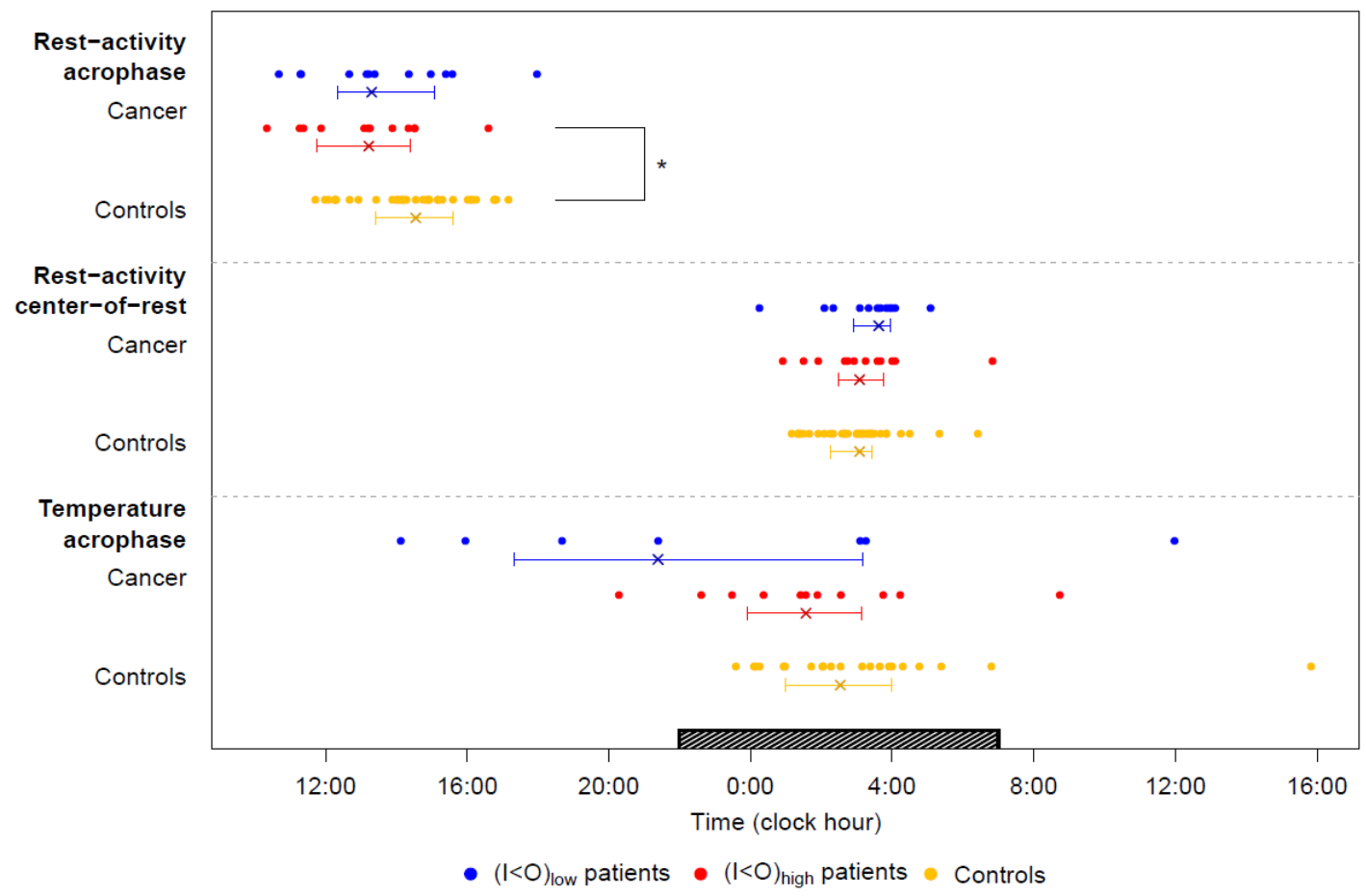

Figure 4. Daily timing of the tele-monitored circadian biomarkers. Median, interquartiles, and individual timings of each circadian biomarker in $(\mathrm{I}<\mathrm{O})_{\text {low }}$ and $(\mathrm{I}<\mathrm{O})_{\text {high }}$ patients and in controls. Median values are marked by a cross; horizontal bars represent interquartile range. Timings for each individual are plotted as dots (for rest-activity, 12 patients for each I < O group, and 33 controls; for temperature, 7 and 11 patients in the $(\mathrm{I}<\mathrm{O})_{\text {low }}$ and $(\mathrm{I}<\mathrm{O})_{\text {high }}$ groups, respectively, and 21 controls). The dark bar on the abscissa represents the night span (22:01 to 7:00). Chest surface temperature acrophase are shown for the participants displaying a significant circadian rhythm. Levels of significance: * $0.01<p \leq 0.05$ (two-tailed Welch's modified $t$-test).

Inter-subject variability was markedly larger for cancer patients compared to controls. A circadian rhythm was estimated with a cosinor modelling approach for 16 out of 22 cancer patients $(73 \%)$, including nine out of 13 with $(\mathrm{I}<\mathrm{O})_{\text {low }}(69 \%)$, and seven out of nine $(78 \%)$ with $(\mathrm{I}<\mathrm{O})_{\text {high }}$, and for 26 out of 30 controls $(87 \%)$.

The rate of subjects with a significant cortisol rhythm was similar between the $(\mathrm{I}<\mathrm{O})_{\text {high }}$ patients and controls $(p=0.70)$. No significant difference between both $\mathrm{I}<\mathrm{O}$ groups was found for any of the cortisol circadian parameters (Figure 6c). Surprisingly, the cortisol amplitude in the $(\mathrm{I}<\mathrm{O})_{\text {high }}$ group was larger than that of controls $(p=0.01)$ but neither mesor nor acrophase differed significantly between both groups.

The median salivary melatonin concentrations increased over time from 18:00 to 23:00 both in cancer patients and in controls, with large between-subject variations in each group (Figure 6b). Baseline melatonin levels were higher in cancer patients than in controls. The evening rise in salivary melatonin levels from baseline was three-fold in cancer patients with $(\mathrm{I}<\mathrm{O})_{\text {low }}$, five-fold in those with $(\mathrm{I}<\mathrm{O})_{\text {high }}$, and six-fold in controls. Twenty patients $(80 \%)$ and 30 controls $(100 \%)$ provided sufficient melatonin samples for dim light melatonin onset (DLMO) computation. However, individual baselines of salivary melatonin could only be identified for six patients (24\%) and 12 controls (40\%), while the estimation for a further seven patients and 12 controls was based on averaged data from the individual 
baseline profiles. Patients in the $(\mathrm{I}<\mathrm{O})_{\text {low }}$ group tended to have an earlier DLMO than those in the $(\mathrm{I}<\mathrm{O})_{\text {high }}$ group $(19: 48$ vs. 21:44, $p=0.08)$. The median DLMO time was at 20:28 in controls (Figure 6d).


Figure 5. Chest surface temperature patterns and boxplots comparing the parameters of the tele-transmitted temperature patterns in $(\mathrm{I}<\mathrm{O})_{\text {low }}$ and $(\mathrm{I}<\mathrm{O})_{\text {high }}$ cancer groups, and in controls. (a) Time plot of chest surface temperature and curve fitting using spectral analysis for an example $(\mathrm{I}<\mathrm{O})_{\text {high }}$ patient with an I $<\mathrm{O}$ value of $99.1 \%$. The color bars on the abscissa represent the patient's self-reported sleeping and physical exercise spans. (b) Time plot of chest surface temperature for an example $(\mathrm{I}<\mathrm{O})_{\text {low }}$ patient with an $\mathrm{I}<\mathrm{O}$ value of $86.5 \%$. (c) Box plots showing the distribution of the chest surface temperature circadian amplitude for the two I $<$ O patient and control groups. Bars represent the extremes and bold lines inside the box plots plot median levels. Values for each individual are plotted as jittered dots to better show the distribution. (d) Bar graphs of the proportion of individuals with a physiologic chest surface temperature in each $\mathrm{I}<\mathrm{O}$ patient group and controls. Levels of significance: ${ }^{* *} 0.001<p \leq 0.01$ (two-tailed Welch's modified $t$-test in (c)); ${ }^{*} 0.01<p \leq 0.05$ (Fisher's exact test in $(\mathbf{d}))$.

\subsection{Sleep}

Six out of the $13(\mathrm{I}<\mathrm{O})_{\text {low }}$ patients $(46 \%)$ were diagnosed with insomnia following their sleep clinics attendance: three due to post-cancer surgery complications, and three with confirmed mild obstructive sleep apnea (OSA) with an apnea-hypopnea index (AHI) of 9.7, 10.9, and 7.9 respectively. One of the OSA patients also suffered from periodic leg movements (Figure 7a). The subjective sleep data revealed a trend towards more sleep problems in the $(\mathrm{I}<\mathrm{O})_{\text {low }}$ group (Figure $\left.7 \mathrm{~b}, \mathrm{c}\right)$, considering 
global sleep score $(p=0.08)$, subjective sleep duration score $(p=0.046)$ in PSQI, and average sleep disturbance score in the M.D. Anderson Symptom Inventory (MDASI) questionnaire $(p=0.024)$.

a
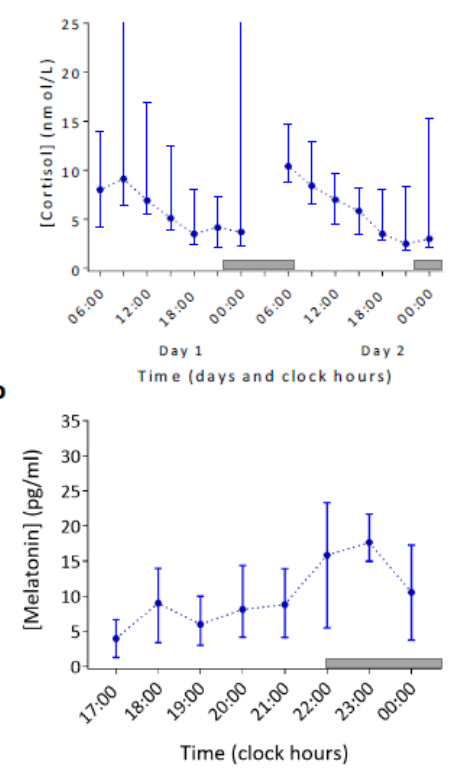
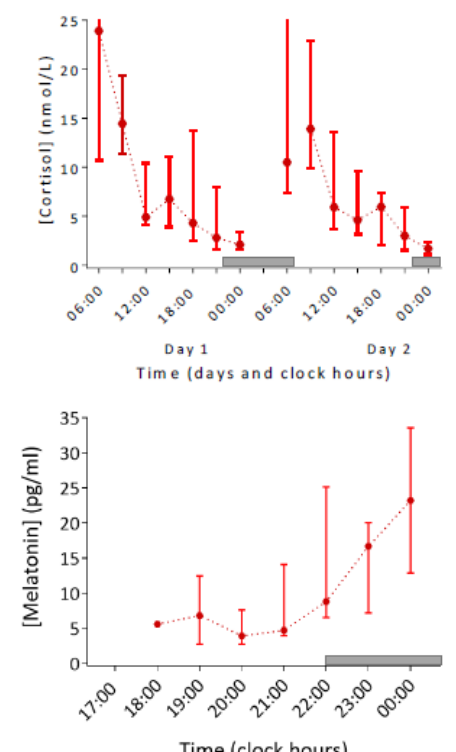


c

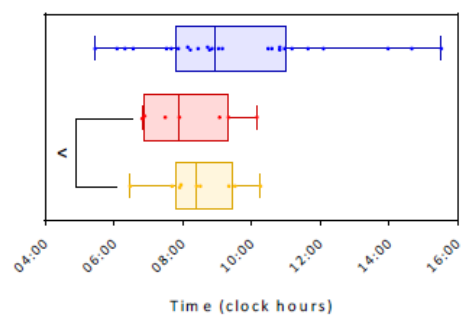

$\square(1<0)_{\text {low }}$ cancer group $\square(1<0)_{\text {high }}$ cancer group $\quad \square$ controls

d

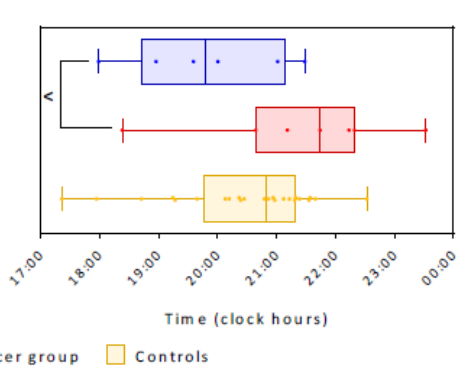

Figure 6. Daily patterns in salivary cortisol and melatonin concentrations in cancer patients and in controls. (a) Circadian changes in salivary cortisol over two consecutive days in the $(\mathrm{I}<\mathrm{O})_{\text {low }}$ patients (blue), in the $(\mathrm{I}<\mathrm{O})_{\text {high }}$ patients (red) and in the controls (yellow). (b) Hourly changes in evening salivary melatonin concentrations in the $(\mathrm{I}<\mathrm{O})_{\text {low }}$ patients (blue), in the $(\mathrm{I}<\mathrm{O})_{\text {high }}$ patients (red), and in the controls (yellow). (c) Box plots of cortisol circadian acrophase in both $\mathrm{I}<\mathrm{O}$ patients' groups and in controls. (d) Box plots of dim light melatonin onset (DLMO) in both $\mathrm{I}<\mathrm{O}$ patients' groups and in controls. In $(\mathbf{a}, \mathbf{b})$, bars represent the interquartile ranges and dots plot the median values. The grey bar on the abscissa represents the night span (22:01 to 07:00). Levels of significance: ${ }^{\wedge} 0.05<p \leq 0.1$ (two-tailed Welch's modified $t$-test).

In controls, none of whom reported any sleep trouble, the subjective evaluation of sleep using a different 10-points scale showed that their sleep quality was rather good, as revealed by an average score of $7.3 \pm 1.5$ A.U.

\subsection{Physical Activity}

Two of the $(\mathrm{I}<\mathrm{O})_{\text {low }}$ patients referred to a physiotherapist displayed signs of physical pathologies, including restless legs (confirmation from sleep clinics), fatigue, and breathlessness. In their daily diaries, ten out of the $11(\mathrm{I}<\mathrm{O})_{\text {high }}$ patients $(91 \%)$ reported daily physical exercise activities of $30 \mathrm{~min}$ or more over at least four study days, as compared to two out of the $13(\mathrm{I}<\mathrm{O})_{\text {low }}$ patients $(15 \%)$ $(p=0.001)$, as well as to 17 of 33 controls $(51 \%)(p=0.03)$. 


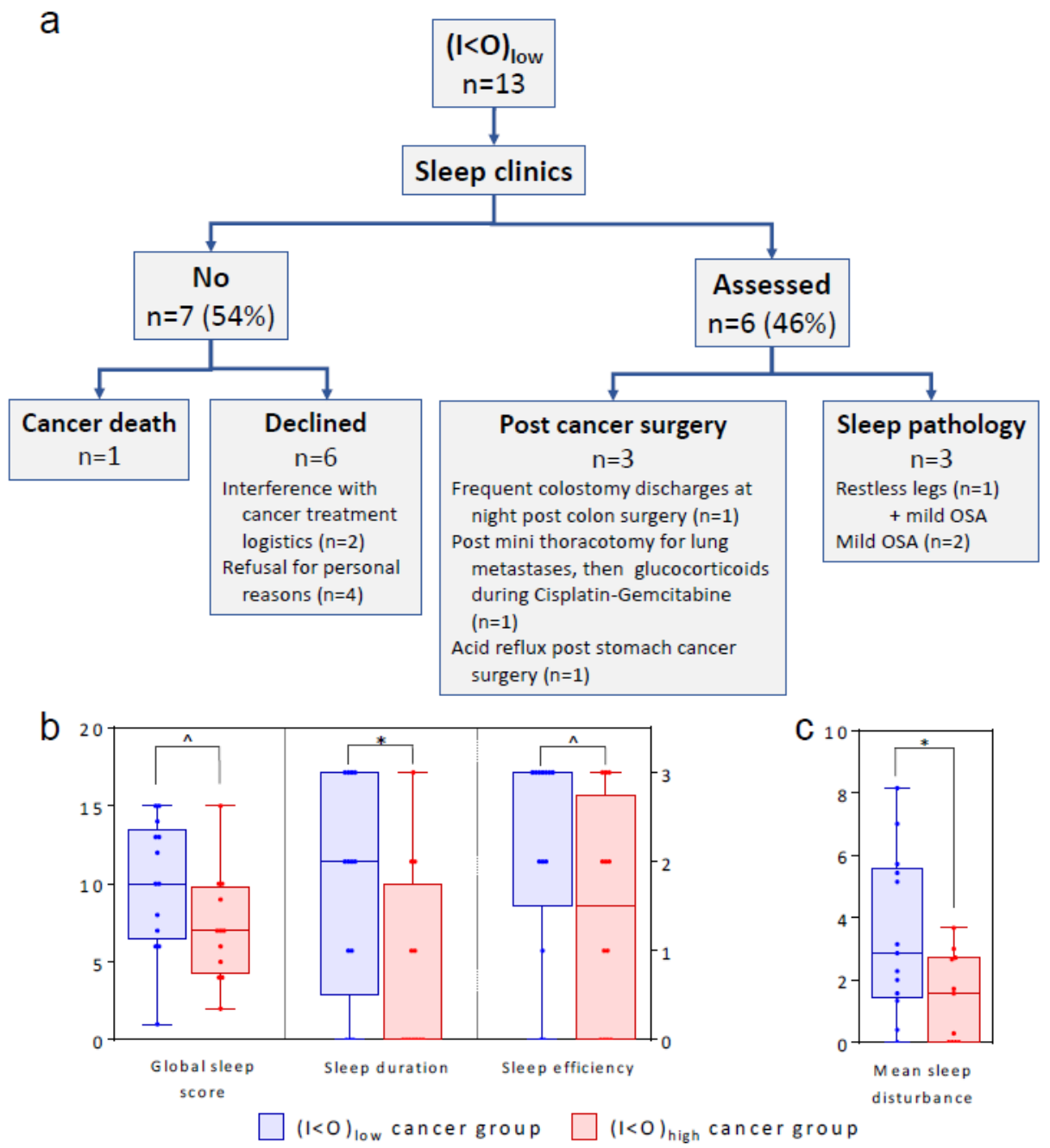

Figure 7. Sleep pathology assessment results and subjective sleep parameters. (a) Consort diagram of the sleep clinics assessment. OSA stands for obstructive sleep apnea. (b) Box plots showing distribution of global score and two selected components of the Pittsburgh sleep quality index (PSQI) in both $\mathrm{I}<\mathrm{O}$ groups. (c) Box plots of the mean score of the sleep disturbance symptom from the MDASI questionnaire in both $\mathrm{I}<\mathrm{O}$ groups. In $(\mathbf{b}, \mathbf{c})$, bars represent the extremes and bold lines inside the box plots plot median levels. Values for each individual are plotted as jittered dots to better show the distribution. Levels of significance: ${ }^{*} 0.01<p \leq 0.05 ;^{\wedge} 0.05<p \leq 0.1$ (two-tailed Welch's modified $t$-test).

\subsection{Relevance of Age, Sex and Cancer on Circadian Parameters}

In controls, age, but not sex, significantly influenced the four main circadian parameters (Supplementary Materials Table S1). Participants aged 40 years or over had reduced I $<$ O and P1-1 ( $p=0.01$ and $p=0.0009$, respectively) as well as phase-advanced circadian activity acrophase and center-of-rest time ( $p=0.01$ for both).

Since all cancer patients were 40 years or older, we further compared the circadian and sleep parameters of the $(\mathrm{I}<\mathrm{O})_{\text {high }}$ cancer patients to the older controls (Appendix B, Table S2). We found that their I $<$ O values were similar (median, $97.3 \%$ vs. $98.3 \%$, respectively; $p=0.15$ ). The majority of the other rest-activity and temperature circadian parameters were also similar although the $(\mathrm{I}<\mathrm{O})_{\text {high }}$ cancer patients were less active, and had more sleep disturbances, as shown by differences in activity level and P1-1 $(p<0.0001$ and $p=0.01$, respectively). 


\subsection{Regression Analysis to Identify Main Actionable Determinants of $(I<O)$}

The domains and factors that significantly influenced the $\mathrm{I}<\mathrm{O}$ in cancer patients using pairwise correlations $(r)$ were:

1. The day-to-day variability in sleep duration estimated with hidden Markov modelling (HMM) $(r=-0.53, p=0.009)$;

2. The self-reported exercise $(r=0.48, p=0.02)$, the rest-activity circadian amplitude $(r=0.73$, $p<0.0001)$, the median activity out-of-bed $(r=0.68, p=0.0003)$, and the level of activity $(r=0.56$, $p=0.005)$;

3. The day-to-day variability in the self-reported retiring time $(r=0.49, p=0.02)$;

4. The physiologic chest temperature rhythm (24-h dominant period and nocturnal acrophase between 22:01 and 07:00, $p=0.03$ );

5. The chronotype score $(r=-0.43, p=0.04)$.

Both the circadian amplitude in rest-activity and sleep duration variability were identified as best predictors of a patient's $\mathrm{I}<\mathrm{O}$, according to multiple linear regression and statistical selection procedures, using parameters from 7-day chest rest-activity time series. The estimated regression equation (Equation (1)), where $\mathrm{E}(\mathrm{I}<\mathrm{O})$ stands for estimated $\mathrm{I}<\mathrm{O}$, was:

$\mathrm{E}(\mathrm{I}<\mathrm{O})=0.1584 *$ chest activity amplitude $(p<0.0001)-2.6695 *$ sleep duration variability $(p=0.0001)$

where the (adjusted) R-squared of the regression was 0.7869 for the sample size of 22 patients. The same covariates also significantly influenced the $\mathrm{I}<\mathrm{O}$ in the controls, i.e.:

1. The HMM-estimated sleep duration variability $(r=-0.53, p=0.002)$;

2. The rest-activity circadian amplitude $(r=0.36, p=0.04)$; but in addition age $(r=-0.48, p=0.006)$.

In the controls, statistical procedures from multiple regression fitting models also selected rest-activity rhythm amplitude and sleep duration variability as the best predictors of the $\mathrm{I}<\mathrm{O}$, together with age. The estimated regression equation (Equation (2)) was as follows:

$\mathrm{E}(\mathrm{I}<\mathrm{O})=-1.300244 *$ sleep duration variability $(p=0.0001)+0.020682 *$ activity amplitude $(p=0.04)-0.035849 *$ age $(p=0.0001)$

with an adjusted R-squared of 0.5858 in 32 controls.

\section{Discussion}

A strong engagement by 25 patients with advanced gastro-intestinal cancer and 33 controls provided a multidimensional data set over one week, with median total protocol compliance rates exceeding 95\%. Results from studies involving wearable sensors and regular patient reported outcome measure (PROM) assessment, have highlighted the paramount importance of the engagement of both patients and health professionals in order to improve outcomes [26,27]. Both studies provided excellent quality data for activity and temperature from the tele-transmitting chest sensor and for the questionnaires completed at home. Neither participants nor carers raised concerns regarding the equipment, and no adverse feelings in the participants' experience were documented. The compliance figures with PROMs in cancer patients were better than those found using the inCASA fixed platform, and compared favorably with other studies using daily mHealth symptoms checklists or even less frequent digital symptom assessment methods [28-30]. While salivary cortisol data were of high quality for almost all participants, melatonin secretion mechanisms might be impaired in cancer patients and in controls older than 40 y.o., for whom DLMO could hardly be precisely computed in real life conditions [31]. Beta-blockers intake could indeed contribute to the lack of technical determination of DLMO for three of four patients on such medications, but played no role for the other patients nor for controls. The intake of paracetamol or non-steroidal anti-inflammatory drugs had no apparent 
effect on the chest surface temperature patterns of cancer patients. Thus, five of six patients on either drug displayed a circadian rhythm, with an acrophase located at night for four of them, i.e., similar to the results in the controls.

As anticipated and consistent with prior reports, we observed a nearly 50:50 percentage split of patients with a good and a poor rest-activity rhythm (threshold for I $<\mathrm{O}$ of 97.5) [10-13]. The circadian rhythm in rest-activity was not significantly influenced by patients' demographics, cancer characteristics, environmental synchronization signals, or lifestyle. Nevertheless, the I $<\mathrm{O}$ index was strongly and consistently correlated with other rest-activity rhythm parameters, each addressing a different perspective on the rest-activity circadian domain. Moreover, the rest-activity rhythm parameters were significantly associated with the occurrence of a physiologic 24-h rhythm in chest surface temperature, involving an acrophase at night. We identified in this study relevant associations between $\mathrm{I}<\mathrm{O}$ and physical activity parameters, subjective and objective, as well as subjective sleep quality and objective sleep duration and timing. The most influential factors on $\mathrm{I}<\mathrm{O}$ in both cancer patients and controls were the indicators in the physical activity domain and the variability in duration in the sleep domain. Some previously undiagnosed sleep disorders that deserve further attention were identified in the cancer patients.

The study in cancer patients (IDEAs) has highlighted that low $\mathrm{I}<\mathrm{O}$ values were associated with disrupted circadian coordination, poor physical activity and irregular daily living activities in cancer patients. Based on the evidence collected here for $(\mathrm{I}<\mathrm{O})_{\text {low }}$ patients without sleep pathology, timed physical exercise during the day, regular times of retiring and meals, and a low dose of (modified-release) hydrocortisone (in case of associated $(\mathrm{I}<\mathrm{O})_{\text {low }}$ and low r24) could be recommended [32-35].

\section{Materials and Methods}

\subsection{Study Designs and Participants}

Two studies, in the sequel named "IDEAs" and "PicaPill", were subject to a similar design, facilitating comparison between cancerous and control participants (Figure 8).

Written informed consent was received from all participants prior to inclusion, and the studies were conducted according to the Helsinki Declaration [36]. For IDEAs, patients with locally advanced or metastatic gastro-intestinal cancer and a good performance status were enrolled at five United Kingdom hospitals, before they received a new chemotherapy protocol. The PicaPill study aimed to identify the influence of age and sex on circadian biomarkers in stratified control participants, and proposed a novel model for the estimation of the internal circadian phase [37]. The adult volunteers in both studies had their chronotype determined using the MEQ [38]. They continuously wore a thoracic sensor containing an accelerometer and skin surface thermometer (Movisens, Karlsruhe, Germany), as well as a wrist-watch with actigraph and luminometer (Motionlogger MicroWatch, Ambulatory Monitoring Inc., Ardsley, NY, USA) and maintained a lifestyle diary for 7 days. Anonymized data from the thoracic sensor were automatically tele-transmitted via GPRS daily. Participants were also asked to provide: (i) 12 saliva samples to be collected every $3 \mathrm{~h}$ in the daytime for 2 days, for the determination of diurnal salivary cortisol patterns; and (ii) 6 saliva samples gathered every hour starting at 19:00 and in dim light, for the DLMO computation.

The cancer patients also completed a PSQI, a HADS, and a reaction to research participation questionnaire (RRPQ) [39-41]. They rated their symptoms according to the MDASI at home each evening for 7 days [42]. 




Figure 8. Study design. Chart showing the similar study designs for cancer patients (IDEAs) and controls (PicaPill). HADS: hospital anxiety and depression scale; MEQ: Morningness-Eveningness Questionnaire; PSQI: Pittsburgh sleep quality index; MDASI: M.D. Anderson Symptom Inventory; RRPQ: reactions to research participation questionnaire.

\subsection{Data Collection and Management}

Tele-transmitted chest sensor data were stored on the server based on HL7 standards (international standards for transfer of clinical and administrative data). Anonymized data were saved on a secure storage server according to the national Data Protection and Freedom of Information Acts guidance.

Data transmission was inspected at least twice a week during the monitoring sessions to ensure adequate data collection. Missing values (typically sensor for a shower or a bath to avoid contact with water) were identified through steady decreases in temperature measures down to room temperature values, and were removed from analyses. Light intensity exposure was measured every minute using 
the wrist actigraph, worn continuously for 7 days. The data from patients were downloaded at the end of the study by the research nurse at the investigational site. The anonymized data file was emailed to the study team. The data from controls were handled directly by the study team. We report here the light exposure data, because of its importance for the synchronization of circadian rhythms and for the interpretation of melatonin secretion patterns.

All salivary samples were stored in the fridge or freezer at the participants' home, and returned at end of study participation to the investigational site for storing at $-80{ }^{\circ} \mathrm{C}$ until hormonal determinations (Surreys Assays LTD, Guildford, Surrey, UK).

The study team accessed the anonymized data on the server. Missing values of chest actigraph and temperature records occurred when the participant removed the sensor, typically for a shower or a bath to avoid contact with water. The missing values were identified through steady decreases in temperature measures down to room temperature values and were removed from analyses.

The tele-transmitted data were analyzed in real time after an initial recording span of $72 \mathrm{~h}$, such that patients whose $\mathrm{I}<\mathrm{O}$ after $72 \mathrm{~h}\left((\mathrm{I}<\mathrm{O})_{72 \mathrm{~h}}\right)$ was lower than $97.5 \%$ were referred to sleep and physiotherapy clinics, including polysomnography or electroencephalography whenever medically-indicated. Obstructive sleep apnea was classified according to the AHI [43].

\subsection{Statistical Methods}

Two-tailed Welch's $t$-tests for continuous variables and Fisher's exact test for categorical variables were used for pairwise comparisons. To identify relations between variables, Spearman correlations were considered. Significance was defined as $p$-value $<0.05$ and possible trends were considered for $0.05<p<0.15$.

\subsubsection{Circadian Parameters}

The $\mathrm{I}<\mathrm{O}$ index is defined as the percentage of activity counts per minute recorded when the subject is in-bed at night, with values lower than the median activity count when the subject is out-of-bed during the daytime. The $\mathrm{I}<\mathrm{O}$ value of cancer patients was first computed using the first $72 \mathrm{~h}$ of recordings from the chest sensor $\left((\mathrm{I}<\mathrm{O})_{72 \mathrm{~h}}\right)$, so as to categorize them in the $(\mathrm{I}<\mathrm{O})_{\text {high }}$ group if $(\mathrm{I}<\mathrm{O})_{72 \mathrm{~h}}$ was above $97.5 \%$ or in the $(\mathrm{I}<\mathrm{O})_{\text {low }}$ group if $(\mathrm{I}<\mathrm{O})_{72 \mathrm{~h}}$ was below or equal to $97.5 \%$, which led to referral to sleep and physiotherapy clinics. $\mathrm{I}<\mathrm{O}$ was also computed at the end of the study over the 7 days of chest activity recordings for all 58 participants

A hidden Markov model was fitted to 5-min aggregated chest rest-activity data, which retrospectively infers the times an individual spent in three different states, that we will define as an inactive/rest (IA), moderately active (MA), and highly active (HA) state, and are specific to the person [25]. The HMM further produces a variety of numerical quantifiers that are of interest to circadian rhythm in rest-activity, such as:

1. The mid values of the MA and HA states which indicate daily activity levels;

2. The rhythm index (RI), with values ranging between 1 , corresponding to best average quality and regularity of the IA state, and 0 , corresponding to poor quality and absence of a consistent rest state in the pattern;

3. The average center-of-rest time of the IA state;

4. P1-1, the estimated probability of staying in the IA state (state 1); when having previously been in this state. P1-1 is positively correlated with $\mathrm{I}<\mathrm{O}$, while the probability [1-(P1-1)] serves as an estimate of rest interruption.

The day-to-day sleep onset, wake up time and length of rest were also estimated via the HMM approach.

In addition, the autocorrelation coefficient at 24-h delay (r24) was computed to characterize the regular overall circadian regularity in rest-activity pattern, with possible values ranging from -1 to +1 . The range of interest usually lies between values around zero for no regularity, and rising values up to 1 indicating a more daily recurring pattern in activity [13]. 


\subsubsection{Spectral Analysis and Cosinor Modelling}

Spectral analysis combined with spectrum-resampling methods was applied to hourly aggregated chest rest-activity, surface temperature, and light data, after missing data were linearly interpolated [24]. Period length was estimated by the dominant spectral period and corresponding amplitude and acrophase (time of estimated maximum) along with $90 \%$ confidence intervals.

The surface temperature rhythm was fitted by a cosinor model (Equation (3)). Data were first smoothed by a 1-h moving average window, then computed as an averaged 24-h profile $y(t)$, and fitted using a two-harmonic cosinor model, with periods $T_{1}=24 \mathrm{~h}$ and $T_{2}=12 \mathrm{~h}$ :

$$
y(t)=M+a_{1} \sin \left(\frac{2 \pi t}{T_{1}}\right)+b_{1} \cos \left(\frac{2 \pi t}{T_{1}}\right)+a_{2} \sin \left(\frac{2 \pi t}{T_{2}}\right)+b_{2} \cos \left(\frac{2 \pi t}{T_{2}}\right)+e(t)
$$

where $y(t)$ is the temperature at time $t, M$ is the mesor (mean level of the fitted cosine function), $a_{1}, a_{2}$ and $b_{1}, b_{2}$ are the coefficients of the cosinor model, and $e(t)$ is the error [44]. Given the periods $T_{1}$ and $T_{2}$, the coefficients were estimated by least-squares linear regression.

Cortisol time series were considered as adequate if at least 9 samples were collected over 2 days. A cosinor model with a period of 24-h was fitted to describe the circadian pattern of salivary cortisol secretion (Equation (4)):

$$
y(t)=M+a \sin \left(\frac{2 \pi t}{T}\right)+b \cos \left(\frac{2 \pi t}{T}\right)+e(t)
$$

where $y(t)$ is the salivary cortisol secretion at time $t ; M$ is the mesor; $a$ and $b$ are real coefficients; $e(t)$ is the error term. Given the period $T=24 \mathrm{~h}, y(t)$ was fitted by a linear regression model. We computed the cortisol mesor, amplitude $\left(\sqrt{a^{2}+b^{2}}\right)$, and acrophase (time of estimated maximum in fitted $\hat{y}$ ), with $90 \%$ confidence intervals, estimated by the bootstrap method [45].

\subsubsection{DLMO Computation}

The dim light conditions required for the DLMO determinations were checked by computing the average level of light and duration of exposure over the $30 \mathrm{~min}$ before each saliva sample collection.

DLMO is commonly computed as the time of the day when melatonin concentration in plasma or saliva exceeds a threshold computed as the mean of 3 consecutive daytime values before melatonin rise plus twice the standard deviation of these 3 points [31]. For those participants with insufficient baseline data, an estimated threshold value was computed as the mean plus twice the standard deviation of the pooled baseline melatonin values in the participants with adequate baseline data.

This estimated threshold was first validated in the participants with adequate baseline data by Pearson's correlation, before its use for all the participants. Distinct estimated thresholds were computed for the patients and the controls.

\subsubsection{Analysis of RACR Domain}

The rest activity circadian rhythm $(R A C R)$ domain was described by the $(\mathrm{I}<\mathrm{O})_{72 \mathrm{~h}}$ value estimated after the initial $72 \mathrm{~h}$ and categorized as $(\mathrm{I}<\mathrm{O})_{\text {low }}$ versus $(\mathrm{I}<\mathrm{O})_{\text {high }}$, and the four circadian parameters ( $\mathrm{I}<\mathrm{O}, \mathrm{P} 1-1, \mathrm{RI}$, and $\mathrm{r} 24)$ computed over 7 days, each describing different aspects of the RACR domain.

Potentially modifiable variables influencing RACR were considered in six functional domains: sleep, physical activity, lifestyle, psychosocial, 'other biomarkers' (chest temperature and salivary cortisol), and symptoms. Non-modifiable factors such as patient's characteristics and cancer characteristics were also examined. Pairwise comparisons were performed to identify adequate variables to use as covariates in regression analysis. Regression analysis was applied by considering the five RACR parameters as dependent variables and the modifiable, as well as non-modifiable variables as potential predictors. A regression model was identified by the global model selection based on the (corrected) Akaike's information criterion (AICc) using the R package MuMIn. Here, we focus on results for $\mathrm{I}<\mathrm{O}$. 


\subsection{Study Approval}

The Research Ethics Committees, Health Research Authority, East Midlands-Leicester Central Research Ethics Committee approved the IDEAs study (IRAS 233972). The PicaPill study was approved by the Ethical Committee of Warwick University (REGO-2017-2055). For both studies, a written informed consent was received from all participants prior to inclusion.

\section{Conclusions}

In conclusion, we found that the longitudinal collection of tele-transmitted rest-activity and body temperature during daily routine for one week were sufficient for the identification of precise and potentially actionable factors for personalized interventions, aiming to improve circadian and sleep alterations. Our study promotes a patient-centered approach based on e-Health platforms and patient engagement. Such a framework challenges the current cancer patient pathways. Indeed, a multi-professional healthcare coordination structure is pivotal for the success of such projects, necessitating a shift in current hospital-centered health care.

Supplementary Materials: The following are available online at http://www.mdpi.com/2072-6694/12/7/1938/s1, Figure S1: Environmental synchronizing signals. Median, interquartiles, and individual median timings of each environmental signal according to either $\mathrm{I}<\mathrm{O}$ cancer group (11 to 13 participants for each signal) or control group (31 to 33 participants), Table S1: Sex or age effects on the rest-activity and chest surface temperature circadian parameters, synchronization signals, cortisol rhythm, and DLMO in the controls, Table S2: Comparison of rest-activity and chest surface temperature circadian parameters, synchronization signals, cortisol rhythm and DLMO between the $(\mathrm{I}<\mathrm{O})_{\text {high }}$ patients and the controls older than 40 years.

Author Contributions: Conceptualization, F.L., S.K., J.B., B.F., D.P.W. and P.I.; Data curation, S.K.; Formal analysis, S.K., Q.H., J.B. and B.F.; Funding acquisition, F.L.; Investigation, F.L., S.K., Q.H., T.Y., Y.A., C.F., M.B., J.F. and P.I.; Methodology, F.L., S.K., Q.H., J.B., B.F. and P.I.; Project administration, F.L. and J.F.; Resources, J.F.; Software, S.K. and Q.H.; Supervision, F.L.; Visualization, S.K. and Q.H.; Writing—original draft, F.L. and S.K.; Writing一review \& editing, F.L., Q.H., T.Y., Y.A., C.F., M.B., J.B., J.F., B.F., D.P.W. and P.I. All authors have read and agreed to the published version of the manuscript.

Funding: This research was funded by Philips Respironics and Warwick University.

Acknowledgments: The study was funded in part by a grant from Philips Respironics (Murrysville, PA, USA) and by Warwick University. INSERM (Paris, France) loaned the PiCADo e-health platforms which were used for both studies. We are grateful to the cancer patients and the control participants who engaged themselves in either study. We thank the clinical research nurses and practitioners who made this research possible, and especially Wendy Saxton, Carolyn Hindmarsh, Cellins Vinod, Tara Chalk and Christine Brannan, the sleep and physiotherapy teams, and especially Michelle Needham, Liz Brohan, Karen Pidlyskyj, Emma Hamilton and Simon Cooper, the Warwick Administrative Teams for handling the administrative aspects, Peter Correa at UHCW and Daniel Hochhauser at UCLH for their contribution to IDEAs, and the Philips team in the UK for assistance regarding polysomnography equipment. We are most grateful to James Mason (Clinical Trial Unit, Warwick Medical School) for chairing the Study Steering Committee of IDEAs, and his personal commitment throughout IDEAs development, and to Franco Cappuccio (Warwick Medical School) for advice and support regarding sleep assessments.

Conflicts of Interest: FL reports biomedical devices loan from INSERM (France) and grant support from Philips Respironics; TY reports grants from Warwick University, during the conduct of the study; YA reports grants and other from Covidien, outside the submitted work; DPW reports personal fees from Philips Respironics, personal fees from Alairion, personal fees from Apnimed, outside the submitted work; PFI reports grants from Philips Respironics, during the conduct of the study. The funders had no role in the design of the study; in the collection, analyses, or interpretation of data; in the writing of the manuscript, or in the decision to publish the results.

\section{Appendix A}

We wondered if the differences, found in circadian biomarkers parameters between the $(\mathrm{I}<\mathrm{O})_{\text {high }}$ or $(\mathrm{I}<\mathrm{O})_{\text {low }}$ patients and the controls, could reflect differences in the recurring environmental signals that synchronize the endogenous circadian rhythms. We addressed this question by analyzing the precise daily diaries that were provided by 24 out of 25 cancer patients and 32 out of 33 controls.

Again, substantial inter-subject differences were apparent regarding the daily-recurrent environmental signals, in both cancer patients and controls (Figure S1). Differences were neither found 
between the cancer patients with $(\mathrm{I}<\mathrm{O})_{\text {low }}$ or $(\mathrm{I}<\mathrm{O})_{\text {high, }}$, nor with controls, regarding the times of retiring and estimated sleep onset ( $p>0.40)$, the times of breakfast, lunch, or dinner $(p>0.07)$, or the acrophase of light exposure $(p=0.34)$. In contrast, however, the $(\mathrm{I}<\mathrm{O})_{\text {high }}$ cancer patients took dinner and retired earlier than the controls ( $p=0.003$ and $p=0.03$, respectively). The fitted HMM further revealed that they also woke up later $(p=0.02)$ and went to sleep earlier $(p=0.02)$ than the controls.

While the times of awakening and sleep onset were found to be significantly influential on the $\mathrm{I}<\mathrm{O}$ in cancer patients, this was not the case for the same parameters recorded in the diaries. We therefore concluded that the daily diary reports, despite their careful annotations, provided no information regarding circadian and sleep cycles that was going beyond the analyses of the tele-transmitted activity and temperature sensor data. Interestingly, no significant correlation was found between the subject's chronotype and any lifestyle or timing parameter based on the circadian biomarkers. This indeed suggested that the adjustment of the central circadian coordination system to the environmental synchronizer varied between subjects irrespective of whether they had cancer or not.

\section{Appendix B}

The phase advance in the older control participants was supported by self-reported and tele-monitored wake-up times ( $p=0.01$ and $p=0.01$ respectively), self-reported retiring times $(p=0.02)$ and tele-monitored sleep onset $(p=0.01)$. We could not identify notable effects of age or sex regarding other variables or parameters, namely level of activity, circadian amplitude, r24, RI, and rest duration, as well as synchronization signals, such as light exposure, times of awakening or retiring, and meal times.

Regarding chest surface temperature, older participants displayed a larger circadian amplitude (spectral analysis, $p=0.04$; cosinor, $p=0.05)$. Females had a higher temperature mesor $(p=0.0002)$ and tended to display a later circadian acrophase $(p=0.07)$.

Neither self-reported sleep quality nor salivary cortisol rhythm parameters varied with age $(p=0.90)$ or sex $(p=0.93)$. Interestingly, the melatonin rise was significantly steeper in the controls who were younger than 40 years, while the average pattern of the older subjects was similar to that of the cancer patients. An individual melatonin baseline was identified for 10 of the 15 controls aged less than 40 years $(67 \%)$, as compared to only 2 of the 15 older controls $(13 \%)(p=0.01)$. The DLMO times did not vary according to age, but they occurred earlier in females $(p=0.04)$.

The $(\mathrm{I}<\mathrm{O})_{\text {high }}$ cancer patients also had a larger circadian cortisol amplitude $(p=0.01)$, rose later in the morning $(p=0.01)$, and had dinner earlier $(p=0.02)$.

\section{References}

1. Grasselli, G.; Zangrillo, A.; Zanella, A.; Antonelli, M.; Cabrini, L.; Castelli, A.; Cereda, D.; Coluccello, A.; Foti, G.; Fumagalli, R.; et al. Baseline Characteristics and outcomes of 1591 patients infected with SARS-CoV-2 admitted to ICUs of the lombardy region, Italy. JAMA 2020, 323, 1574-1581. [CrossRef] [PubMed]

2. Onder, G.; Rezza, G.; Brusaferro, S. Case-fatality rate and characteristics of patients dying in relation to COVID-19 in Italy. JAMA 2020, 323, 1775-1776. [CrossRef] [PubMed]

3. Dadashzadeh, $\mathrm{S}$. The role of patient-centered medical home recognition in addressing public health priorities. Health Care Manag. 2019, 38, 124-145. [CrossRef] [PubMed]

4. Liang, H.; Tao, L.; Ford, E.W.; Beydoun, M.A.; Eid, S.M. The patient-centered oncology care on health care utilization and cost: A systematic review and meta-analysis. Health Care Manag. Rev. 2018, 10. [CrossRef]

5. Cederroth, C.R.; Albrecht, U.; Bass, J.; Brown, S.A.; Dyhrfjeld-Johnsen, J.; Gachon, F.; Green, C.B.; Hastings, M.H.; Helfrich-Forster, C.; Hogenesch, J.B.; et al. Medicine in the fourth dimension. Cell Metab. 2019, 30, $238-250$. [CrossRef]

6. Innominato, P.F.; Roche, V.P.; Palesh, O.G.; Ulusakarya, A.; Spiegel, D.; Levi, F.A. The circadian timing system in clinical oncology. Ann. Med. 2014, 46, 191-207. [CrossRef]

7. Hastings, M.H.; Reddy, A.B.; Maywood, E.S. A clockwork web: Circadian timing in brain and periphery, in health and disease. Nat. Rev. Neurosci. 2003, 4, 649-661. [CrossRef] 
8. Dallmann, R.; Okyar, A.; Levi, F. Dosing-time makes the poison: Circadian regulation and pharmacotherapy. Trends Mol. Med. 2016, 22, 430-445. [CrossRef]

9. Roenneberg, T.; Merrow, M. The circadian clock and human health. Curr. Biol. 2016, 26, R432-R443. [CrossRef]

10. Innominato, P.F.; Focan, C.; Gorlia, T.; Moreau, T.; Garufi, C.; Waterhouse, J.; Giacchetti, S.; Coudert, B.; Iacobelli, S.; Genet, D.; et al. Circadian rhythm in rest and activity: A biological correlate of quality of life and a predictor of survival in patients with metastatic colorectal cancer. Cancer Res. 2009, 69, 4700-4707. [CrossRef] [PubMed]

11. Innominato, P.F.; Komarzynski, S.; Palesh, O.G.; Dallmann, R.; Bjarnason, G.A.; Giacchetti, S.; Ulusakarya, A.; Bouchahda, M.; Haydar, M.; Ballesta, A.; et al. Circadian rest-activity rhythm as an objective biomarker of patient-reported outcomes in patients with advanced cancer. Cancer Med. 2018, 7, 4396-4405. [CrossRef] [PubMed]

12. Levi, F.; Dugue, P.A.; Innominato, P.; Karaboue, A.; Dispersyn, G.; Parganiha, A.; Giacchetti, S.; Moreau, T.; Focan, C.; Waterhouse, J.; et al. Wrist actimetry circadian rhythm as a robust predictor of colorectal cancer patients survival. Chronobiol. Int. 2014, 31, 891-900. [CrossRef] [PubMed]

13. Mormont, M.C.; Waterhouse, J.; Bleuzen, P.; Giacchetti, S.; Jami, A.; Bogdan, A.; Lellouch, J.; Misset, J.L.; Touitou, Y.; Levi, F. Marked 24-h rest/activity rhythms are associated with better quality of life, better response, and longer survival in patients with metastatic colorectal cancer and good performance status. Clin. Cancer Res. 2000, 6, 3038-3045. [PubMed]

14. Sephton, S.E.; Sapolsky, R.M.; Kraemer, H.C.; Spiegel, D. Diurnal cortisol rhythm as a predictor of breast cancer survival. J. Natl. Cancer Inst. 2000, 92, 994-1000. [CrossRef]

15. Innominato, P.; Komarzynski, S.; Karaboue, A.; Ulusakarya, A.; Bouchahda, M.; Haydar, M.; Bossevot-Desmaris, R.; Mocquery, M.; Plessis, V.; Levi, F. Home-based e-health platform for multidimensional telemonitoring of symptoms, body weight, sleep, and circadian activity: Relevance for chronomodulated administration of irinotecan, fluorouracil-leucovorin, and oxaliplatin at home-results from a pilot study. JCO Clin. Cancer Inf. 2018, 2, 1-15. [CrossRef]

16. Innominato, P.F.; Komarzynski, S.; Mohammad-Djafari, A.; Arbaud, A.; Ulusakarya, A.; Bouchahda, M.; Haydar, M.; Bossevot-Desmaris, R.; Plessis, V.; Mocquery, M.; et al. Clinical relevance of the first domomedicine platform securing multidrug chronotherapy delivery in metastatic cancer patients at home: The inCASA European project. J. Med. Internet Res. 2016, 18, e305. [CrossRef] [PubMed]

17. Natale, V.; Innominato, P.F.; Boreggiani, M.; Tonetti, L.; Filardi, M.; Parganiha, A.; Fabbri, M.; Martoni, M.; Levi, F. The difference between in bed and out of bed activity as a behavioral marker of cancer patients: A comparative actigraphic study. Chronobiol. Int. 2015, 32, 925-933. [CrossRef] [PubMed]

18. Minors, D.; Akerstedt, T.; Atkinson, G.; Dahlitz, M.; Folkard, S.; Levi, F.; Mormont, C.; Parkes, D.; Waterhouse, J. The difference between activity when in bed and out of bed. I. healthy subjects and selected patients. Chronobiol. Int. 1996, 13, 27-34. [CrossRef]

19. Innominato, P.F.; Mormont, M.C.; Rich, T.A.; Waterhouse, J.; Levi, F.A.; Bjarnason, G.A. Circadian disruption, fatigue, and anorexia clustering in advanced cancer patients: Implications for innovative therapeutic approaches. Integr. Cancer Ther. 2009, 8, 361-370. [CrossRef]

20. Mormont, M.C.; Waterhouse, J. Contribution of the rest-activity circadian rhythm to quality of life in cancer patients. Chronobiol. Int. 2002, 19, 313-323. [CrossRef]

21. Chang, W.P.; Lin, C.C. Correlation between rest-activity rhythm and survival in cancer patients experiencing pain. Chronobiol. Int. 2014, 31, 926-934. [CrossRef] [PubMed]

22. Innominato, P.F.; Giacchetti, S.; Bjarnason, G.A.; Focan, C.; Garufi, C.; Coudert, B.; Iacobelli, S.; Tampellini, M.; Durando, X.; Mormont, M.C.; et al. Prediction of overall survival through circadian rest-activity monitoring during chemotherapy for metastatic colorectal cancer. Int. J. Cancer 2012, 131, 2684-2692. [CrossRef] [PubMed]

23. Komarzynski, S.; Huang, Q.; Innominato, P.F.; Maurice, M.; Arbaud, A.; Beau, J.; Bouchahda, M.; Ulusakarya, A.; Beaumatin, N.; Breda, G.; et al. Relevance of a mobile internet platform for capturing interand intrasubject variabilities in circadian coordination during daily routine: Pilot study. J. Med. Internet Res. 2018, 20, e204. [CrossRef] [PubMed]

24. Costa, M.J.; Finkenstadt, B.; Roche, V.; Levi, F.; Gould, P.D.; Foreman, J.; Halliday, K.; Hall, A.; Rand, D.A. Inference on periodicity of circadian time series. Biostatistics 2013, 14, 792-806. [CrossRef] [PubMed] 
25. Huang, Q.; Cohen, D.; Komarzynski, S.; Li, X.M.; Innominato, P.; Levi, F.; Finkenstadt, B. Hidden markov models for monitoring circadian rhythmicity in telemetric activity data. J. R. Soc. Interface 2018, 15. [CrossRef] [PubMed]

26. Osborn, J.; Ajakaiye, A.; Cooksley, T.; Subbe, C.P. Do mHealth applications improve clinical outcomes of patients with cancer? A critical appraisal of the peer-reviewed literature. Support. Care Cancer 2020, 28, 1469-1479. [CrossRef] [PubMed]

27. Rathbone, A.L.; Clarry, L.; Prescott, J. Assessing the efficacy of mobile health apps using the basic principles of cognitive behavioral therapy: Systematic review. J. Med. Internet Res. 2017, 19, e399. [CrossRef]

28. Basch, E.; Dueck, A.C.; Rogak, L.J.; Minasian, L.M.; Kelly, W.K.; O'Mara, A.M.; Denicoff, A.M.; Seisler, D.; Atherton, P.J.; Paskett, E.; et al. Feasibility assessment of patient reporting of symptomatic adverse events in multicenter cancer clinical trials. JAMA Oncol. 2017, 3, 1043-1050. [CrossRef]

29. Benze, G.; Nauck, F.; Alt-Epping, B.; Gianni, G.; Bauknecht, T.; Ettl, J.; Munte, A.; Kretzschmar, L.; Gaertner, J. PROutine: A feasibility study assessing surveillance of electronic patient reported outcomes and adherence via smartphone app in advanced cancer. Ann. Palliat. Med. 2019, 8, 104-111. [CrossRef]

30. Berry, D.L.; Blonquist, T.M.; Nayak, M.M.; Grenon, N.; Momani, T.G.; McCleary, N.J. Self-care support for patients with gastrointestinal cancer: iCancerHealth. Appl. Clin. Inf. 2018, 9, 833-840. [CrossRef]

31. Burgess, H.J.; Wyatt, J.K.; Park, M.; Fogg, L.F. Home circadian phase assessments with measures of compliance yield accurate dim light melatonin onsets. Sleep 2015, 38, 889-897. [CrossRef] [PubMed]

32. Frank, E.; Kupfer, D.J.; Thase, M.E.; Mallinger, A.G.; Swartz, H.A.; Fagiolini, A.M.; Grochocinski, V.; Houck, P.; Scott, J.; Thompson, W.; et al. Two-year outcomes for interpersonal and social rhythm therapy in individuals with bipolar I disorder. Arch. Gen. Psychiat. 2005, 62, 996-1004. [CrossRef] [PubMed]

33. Longo, V.D.; Panda, S. Fasting, Circadian Rhythms, and Time-Restricted Feeding in Healthy Lifespan. Cell Metab. 2016, 23, 1048-1059. [CrossRef] [PubMed]

34. Stewart, P.M. Modified-release hydrocortisone: Is it time to change clinical practice? J. Endocr. Soc. 2019, 3, 1150-1153. [CrossRef] [PubMed]

35. Thomas, J.M.; Kern, P.A.; Bush, H.M.; McQuerry, K.J.; Black, W.S.; Clasey, J.L.; Pendergast, J.S. Circadian rhythm phase shifts caused by timed exercise vary with chronotype. JCI Insight 2020, 5, e134270. [CrossRef]

36. Carlson, R.V.; Boyd, K.M.; Webb, D.J. The revision of the declaration of helsinki: Past, present and future. Br. J. Clin. Pharm. 2004, 57, 695-713. [CrossRef]

37. Komarzynski, S.; Bolborea, M.; Huang, Q.; Finkenstadt, B.; Levi, F. Predictability of individual circadian phase during daily routine for medical applications of circadian clocks. JCI Insight 2019, 4, e130423. [CrossRef]

38. Horne, J.A.; Ostberg, O. A self-assessment questionnaire to determine morningness-eveningness in human circadian rhythms. Int. J. Chronobiol. 1976, 4, 97-110.

39. Kassam-Adams, N.; Newman, E. The reactions to research participation questionnaires for children and for parents (RRPQ-C and RRPQ-P). Gen. Hosp. Psychiatry 2002, 24, 336-342. [CrossRef]

40. Buysse, D.J.; Reynolds, C.F., 3rd; Monk, T.H.; Berman, S.R.; Kupfer, D.J. The pittsburgh sleep quality index: A new instrument for psychiatric practice and research. Psychiatry Res. 1989, 28, 193-213. [CrossRef]

41. Zigmond, A.S.; Snaith, R.P. The hospital anxiety and depression scale. Acta Psychiatr Scand. 1983, 67, 361-370. [CrossRef]

42. Cleeland, C.S.; Mendoza, T.R.; Wang, X.S.; Chou, C.; Harle, M.T.; Morrissey, M.; Engstrom, M.C. Assessing symptom distress in cancer patients: The M.D. anderson symptom inventory. Cancer 2000, 89, 1634-1646. [CrossRef]

43. Ruehland, W.R.; Rochford, P.D.; O'Donoghue, F.J.; Pierce, R.J.; Singh, P.; Thornton, A.T. The new AASM criteria for scoring hypopneas: Impact on the apnea hypopnea index. Sleep 2009, 32, 150-157. [CrossRef] [PubMed]

44. Cornelissen, G. Cosinor-based rhythmometry. Biol. Med. Model. 2014, 11, 16. [CrossRef] [PubMed]

45. Zoubir, A.M.; Iskander, D.R. Bootstrap Techniques for Signal Processing; Cambridge University Press: Cambridge, UK, 2004.

(C) 2020 by the authors. Licensee MDPI, Basel, Switzerland. This article is an open access article distributed under the terms and conditions of the Creative Commons Attribution (CC BY) license (http://creativecommons.org/licenses/by/4.0/). 